\title{
The effect of mood induction in a risky decision-making task
}

\author{
PATRICIA J. DELDIN and IRWIN P. LEVIN \\ The University of Iowa, Iowa City, Iowa
}

\begin{abstract}
The Velten mood induction procedure was used to create positive, negative, and neutral mood states in subjects who were asked to evaluate a series of risk-taking scenarios. Significant mood effects were found in the evaluations of the first-and most personal-scenario. Subjects in the positive state were most apt to indicate a willingness to risk a medical operation, and subjects in the negative state were least willing to take the risk. Results were discussed in terms of the relationship between mood and the framing of information in risky decision making. Both a positive mood and a positive frame produce more favorable evaluations of a stimulus than do a negative mood and a negative frame.
\end{abstract}

Studies of the effect of mood on behavior have shown that the induction of positive affect results in more positive attitudes, evaluations, and memories than does induction of neutral or negative affect (Bower, 1981; Isen, Shalker, Clark, \& Karp, 1978; Teasdale \& Taylor, 1981). Some of these studies focused on mood effects on memory and posited that the relationship between mood and behavior is mediated by cognitive processes affecting recall. For example, being put in a pleasant mood may cue other pleasant associations, resulting in better recall of positive events.

Paralleling this line of research is the research on framing effects in decision making conducted by Kahneman and Tversky (1979; Tversky \& Kahneman, 1981) and by Levin and his colleagues (Levin, 1985; Levin, Johnson, Deldin, et al., in press; Levin, Johnson, Russo, \& Deldin, 1985). This research shows that evaluation of choice alternatives may be changed drastically when descriptions of the same alternatives are switched from a positive frame to a negative frame. For example, subjects are more willing to say that they will take a gamble when it is expressed in terms of probability of winning than when it is expressed in terms of probability of losing. Levin et al. (1985) speculate that this may be because a positive frame is more apt to be associated with favorable outcomes and a negative frame is more apt to be associated with unfavorable outcomes.

Viewed in this light, framing effects and mood induction effects may be related. Both effects may be mediated by the tendency to evaluate stimuli positively or negatively under varying conditions. Although research on the effects of framing on risky decision making has contrasted

This paper is based on an honors project conducted by the first author under the supervision of the second author. The authors would like to thank Richard D. Johnson for his help on this project. Requests for reprints should be sent to I. P. Levin, Department of Psychology, The University of lowa, Iowa City, IA 52242. positive and negative conditions, the little research that has been done on positive affect in decision making (Isen \& Patrick, 1983) has concentrated on contrasts between positive conditions (e.g., the awarding of gifts) and neutral conditions (lack of awards). The present study utilizes the Velten mood induction procedure (Velten, 1968), which allows for creation of negative as well as positive and neutral mood conditions. We will examine how decision making differs between positive, negative, and neutral mood conditions. We will then see if differences in how the same risky decision task is evaluated by persons in different moods parallel differences observed when information is framed differently.

\section{METHOD}

\section{Decision-Making Task}

Subjects were given five hypothetical risk-taking scenarios to evaluate. In each sceriario, a "yes" response indicated that the subject was willing to risk the status quo to have a specified chance of gaining benefit. The scenarios involved electing an operation which, if successful, would alleviate back pain but, if not successful, would cause worse pain; taking a chance on leaving a current job to possibly gain a better job; playing a gamble which could either lose or gain money; converting to the manufacture of a new product which could prove either more or less successful than the original product; and planning an outdoor function under conditions of threatening weather. Because of its unique importance in the results, the back operation scenario is presented verbatim below.

Try to imagine that you have been afflicted with a disease that causes pain in the lower back. The pain is not severe but is rather uncomfortable. This condition is chronic. There is an operation available that has been thoroughly tested and is known to cure the pain in $75 \%$ of the cases. However, for the other $25 \%$ the pain returns and is reportedly three times as great as it was originally.

The subjects' task was to indicate whether or not they would elect the operation and to rate their degree of confidence in that decision on a scale of $1-20$.

\section{Mood Induction}

Prior to receiving the risk-taking scenarios, each subject was assigned to the positive, negative, or neutral mood induction condition. The Velten 
mood induction procedure (VMIP) was used to create these conditions. In this procedure, each subject read a series of 60 statements, one every $20 \mathrm{sec}$. In the positive or "elation" condition, the statements started with "Today is neither better nor worse than any other day," and became progressively more positive, with statements like "God, I feel great!" appearing at the end. The negative or "depression" condition started with the same neutral statement, but the statements became progressively more negative, ending with the statement, "I want to go to sleep and never wake up." In the neutral condition, the statements remained neutral throughout.

\section{Procedure}

For ethical reasons, it was not desired to induce a negative mood state in individuals who were already depressed. Therefore, each subject was given the Beck Depression Inventory (BDI; Beck, Ward, Mendelsohn, Mock, \& Erbaugh, 1961) at the beginning of the experimental session. For present purposes, a Beck score of higher than 8 was considered sufficient to preclude a subject from being assigned to the negative condition. These subjects were assigned to one of the other conditions but were excluded from the primary data analyses.

After a short period for scoring the BDI and assigning a subject to a mood-state condition, mood was manipulated through the VMIP. Each statement on the VMIP was printed on a different page of a booklet. Subjects wore earphones connected to a tape recorder which sounded tones every $20 \mathrm{sec}$ to signal when to turn a page. This procedure was followed immediately by presentation of the five risky decision scenarios, each on a separate page of a new booklet. Subjects proceeded through this booklet at their own paces. Each scenario required a discrete choice (i.e., whether or not to take the risk) and a confidence rating.

Because the duration of the mood induction effect is known to be short (perhaps less than $10 \mathrm{~min}$ according to Frost \& Green, 1982), the scenarios were given in a fixed order. The back operation scenario described earlier was thought to be the most personal and potent scenario; it was given first while the likelihood of a mood induction effect was greatest. Following completion of the scenarios, those subjects in the negative condition were administered a mood-normalization procedure in which they read, at their own paces, the statements from the positive condition.

\section{Subjects}

Twenty-four subjects (12 male, 12 female) scoring 8 or less on the BDI were assigned to each the positive and negative mood conditions; 12 subjects ( 6 male, 6 female) were assigned to the neutral condition. An additional 12 subjects ( 3 male, 9 female) scored higher than 8 on the BDI and were not included in the analyses that follow. Aside from this latter group, assignment of subjects resulted in groups that did not differ significantly on depression scores.

\section{RESULTS}

Responses were scored by combining discrete choices with confidence ratings. The risky choice (e.g., electing to have the back operation) was scored as " + ", and the other choice (refusing the operation) was scored as " - ." Scores thus ranged from +20 (extreme confidence in the risky choice) to -20 (extreme confidence in the nonrisky choice).

There was a significant effect of mood induction condition on responses to the back operation scenario $[F(2,54)$ $=4.43, p<.02]$. As shown in Figure 1, risk-taking scores for both male and female subjects were highest in the positive condition and lowest in the negative condition, with the scores for subjects in the neutral condition falling in the middle. The linear component of this effect was statistically significant $(p<.01)$, and deviations from linearity were nonsignificant. Neither the effect of

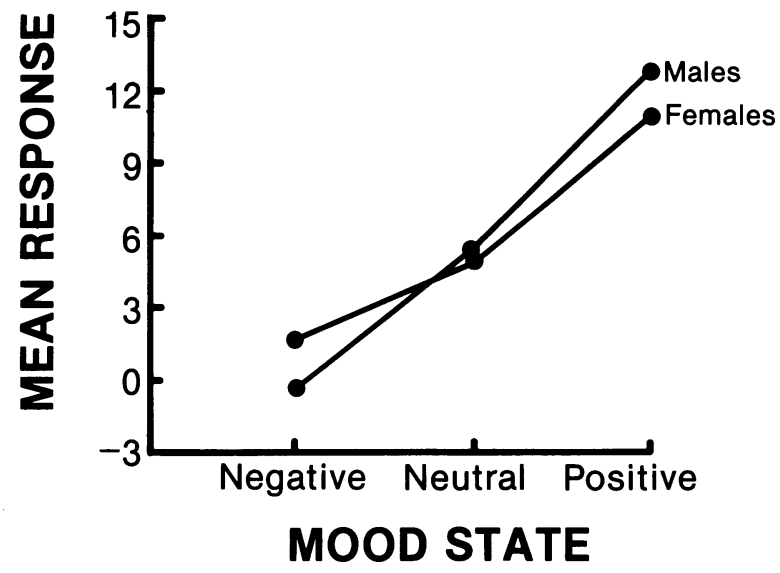

Figure 1. Mean risk-taking response as a function of gender and mood-state condition (back operation scenario).

gender nor the interaction of gender and mood were statistically significant. None of the remaining four scenarios produced statistically significant mood effects. Only one scenario produced a marginally significant gender effect.

\section{DISCUSSION}

The effect of mood induction on risk-taking responses observed here extends earlier work (e.g., Isen \& Patrick, 1983) by including negative as well as positive and neutral mood states. The significant difference between responses in the positive and negative conditions parallels the difference observed when the same objective stimulus is alternately framed in positive or negative terms. This supports the view that both mood effects and framing effects are mediated by differences in evaluating stimuli in different contexts. Both a positive mood and a positive frame produce more favorable evaluations of a stimulus than do a negative mood and a negative frame.

The persistence of the effect of mood induction on risky decision making warrants further work. The lack of significant mood effects beyond the first scenario in the present study could have been due to the dissipation of the effect or could represent a task interaction effect such as that reported by Isen and Patrick (1983). In any case, it is clear that individual and contextual differences in response to risk-taking situations represent important areas of study in decision making. Both the mood the decision maker is in and the way information is framed appear to be key sources of variance.

\section{REFERENCES}

Beck, A. T., Ward, C. H., Mendelsohn, M., Mock, J., \& ERBaUGH, J. (1961). An inventory for measuring depression. Archives of General Psychiatry, 4, 561-571.

Bower, G. H. (1981). Mood and memory. American Psychologist, 2, 129-148.

Frost, R. O., \& GREen, M. L. (1982). Velton mood induction procedure effects: Duration and postexperimental removal. Personality \& Social Psychology Bulletin, 8, 341-347.

Isen, A. M., \& PATRICK, R. (1983). The effect of positive feelings on risk taking: When the chips are down. Organizational Behavior \& Human Performance, 31, 194-202.

Isen, A. M., Shalker, T. E., Clark, M. S., \& KarP, L. (1978). Affect, accessibility of material in memory, and behavior: A cognitive loop? Journal of Personality \& Social Psychology, 36, 1-12.

Kahneman, D., \& TVersky, A. (1979). Prospect theory: An analysis of decision under risk. Econometrica, 47, 263-291. 
LEVIN, I. P. (1985). How changes in price and salary affect economic satisfaction: Information integration models and inference processes. Journal of Economic Psychology, 6, 143-155.

Levin, I. P., Johnson, R. D., Deldin, P. J., Carstens, L. M., CresSEY, L. J., \& DAVIS, C. R. (in press). Framing effects in decisions with completely and incompletely described alternatives. Organizational Behavior \& Human Decision Processes.

Levin, I. P., Johnson, R. D., Russo, C. P., \& Deldin, P. J. (1985) Framing effects in judgment tasks with varying amounts of information. Organizational Behavior \& Human Decision Processes, 36, 362-377.
TEASDAle, J. D., \& TAYLOR, R. (1981). Induced mood and accessibility of memories: An effect of mood state or induction procedure? British Journal of Clinical Psychology, 20, 39-48.

TVERSKY, A., \& KAHNEMAN, D. (1981). The framing of decisions and the psychology of choice. Science, 211, 453-458.

Velten, E. (1968). A laboratory task for induction of mood states. Behaviour Research \& Therapy, 6, 473-482.

(Manuscript received for publication September 9, 1985.) 